directions from the sun for some considerable distance all round it, the totality of radiation from that portion of the heavens may not be so much inferior to what it is when there is none of that slight cirrus haze there. But still we have haze enough in the lower regions, and besides that we have water in an invisible state of vapour, and Dr. Tyndall has shown that that absorbs with great avidity a portion of the heat rays. Those, how ever, are mainly rays of very low refrangibility. Still the absorption of these may very sensibly affect the totality of radiation received from the sun. How then shall we, if possible, get rid of these sources of disturbance? The best plan seems to be to take observations at a considerable altitude, where if possible you may get many thousand feet above the level of the sea and get rid of the lower, dustier, hazier portion of the atmosphere, and get rid also of by far the greater portion of the aqueous vapour, which by itself alone would absorb a portion of the heat. That is what the Committee on Solar Physics have attempted to do. We contemplate having actinometric observations made in the north of India. Of course, if observations are to be continued, it is not sufficient to go to some high mountain. You must go to some habitable place where the observer can live and be in some sort of comfort. Now in the Himalayas you may get up to many thousand feet and yet be still within reach of human habitations; or what is better still, if you cross the range and go over into Thibet, you have there a high table land many thousand feet above the level of the sea, with a sky usually cloudless, and where observations of this kind may, it is hoped, be made with success for a considerable period together, and the result may, we hope, in time throw light on the question whether or no there is in reality a change in the amount of radiation received from the sun, and whether the amount of that change is sufficient to make any material difference in the meteorological conditions of our globe.

I have spoken of meteorological elements in which various observers suspected that they saw some indications at least of a decennial, or nearly decennial, period. Speculations have been made as to whether there is not a decennial period, or something of the kind, traceable even in the occurrence of Indian famines. If so, there may be some very close relationship between the solar spots and these famines. At first sight one would be disposed to say, "What possible connection can sun-spots and famines have with one another? You might as well speak of the connection between comets and wars!" But when we go deeper below the surface, and study carefully the phenomena presented to our view, we see that a possible connection between such apparently remote things as sun-spots and famines may not be chimerical ; and there is no saying what practical application may in the end result from a study of solar phenomena undertaken in the first instance for a purely scientific object.

\section{A PRISMATIC OPTOMETER}

$\mathrm{T}$ is well known that in the normal eye, with its accom. modation relaxed, parallel rays of light, that is, those from distant objects, are brought to a focus on the retina. Rays from near objects are divergent, and if they enter such an eye they are not brought to a focus on the retina, but would be at some point behind it. In order that they may be so brought to a focus and form a distinct image on the retina, an effort of accommodation is necessary. This is performed by a small muscle called the ciliary muscle, inside the eyeball, the ultimate effect of whose contraction is an alteration in the shape and perhaps the condition of the lens, which causes the rays to be more strongly refracted, and brings them to a focus on the retina. The effect is in fact the same as if a convex lens were added to the optical system of the eye. As age advances, the muscle and lens become stiffer, and work with difficulty. They are relieved of part of their work by putting a convex glass in front of the eye. Hypermetropia is a condition in which the axis of the eyeball is too short, compared with the refracting power of the lens. In it an effort of accommodation is necessary to see even distant objects clearly, and a still stronger effort to see near objects. A person suffering from it requires convex glasses. When both eyes are used together, the optic axes of both are directed to the object, so that in looking at a distant object they are directed parallel, and in looking at a near one they converge. These movements are effected by the external muscles of the eyeball, which are supplied by branches of the

$x$ "On a Prismatic Optometer," by Tempest Anderson, M.D., B.Sc., read at the York meeting of the British Association. same nerve as the ciliary muscle. As a fact these movements of the ciliary muscle and of the external muscles of the eyeball are associated, or habitually performed in conjunction; that is, the brain has become accustomed to send an impulse to the one set of muscles proportionate to that sent by the other. Any disturbance of this association can only be accomplished by a distinct effort which, if severe or long continued, is apt to be painful. Suppose a man has become presbyopic, i.e. his accommodation has gradually become stiff, and its range reduced. In order to accommodate for rays from an object at the ordinary reading distance of ten or twelve inches, he has now to exert an effort equal perhaps to what he would have employed when young on one four inches off, but the change bas been gradual, and the convergence of the eyes for twelve inches has become associated with this amount of effort. If he now use convex glasses of suitable power, the want of refracting power is supplied, the effort of accommodation is reduced to its natural amount, but the amount of convergence which has become associated with this small effort is now insufficient, and the eyes, instead of converging to twelve inches, converge on a point several feet distant, so that double vision would be produced, unless by a distinct effort the eyes were converged more, and

\section{Eye End of D! T.Andersoris Prismatic Opiometer.}
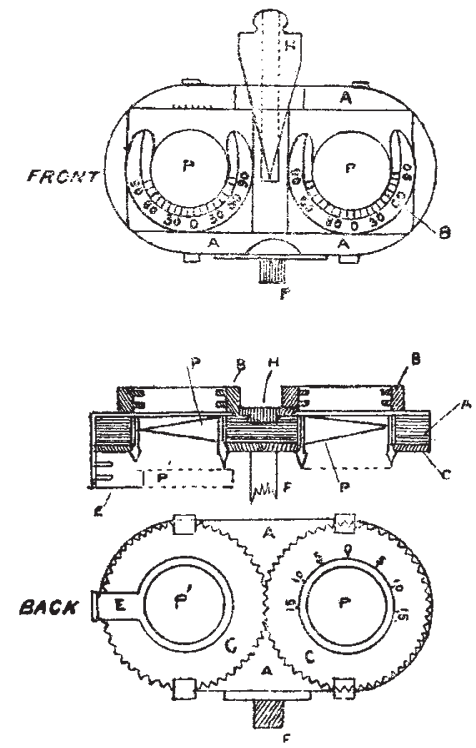

$A$, main frame carried by $F$, graduated rod ; $C$, rotating frame carrying $P P$, prisms ; $\mathrm{E}$, frame carrying $\mathrm{P}^{\prime}$, third prism; $\mathrm{H}$, wedge to separate $\mathrm{B} \mathrm{B}$ frames for lenses.

this effort is often painful, and is expressed by the term that the spectacles "draw" the eyes. After a time new associations are formed, and the spectacles can be used comfortably; but this does not happen in all cases, and for these it is necessary to grind the lenses on glasses of prismatic section. The action of the prism is so to bend the pencils of rays coming to the eyes that they appear to diverge from a point corresponding to the new focal distance of the eyes provided with the spectacles. Sometimes the amount of prismatic effect required is calculated, but the calculition, being based on general considerations, does not always suit individual persons; at other times prismatic glasses from a trial case, are combined with the calculated spherical, or spherical and cylindrical glasses, until one is found with which vision is comfortable. In many cases it is not necessary to use glasses specially ground on prisms, but sufficient to move the centre of the glasses nearer together. The glass being thicker in the centre, looking through the part near the edge produces an amount of prismatic effect which is often sufficient. If concave glasses are used, as in cases of short sight, then they must be further apart than the distance of the eyes, in in order to produce this effect. The object of the instrument exhibited is to find experimentally the amount of prismatic power, and the distance of the centre of the lenses which is 
required in any individual case. Two circular frames each $2 \frac{1}{2}$ inches in diameter, and with teeth cut in their edges, are mounted, so that the teeth gear into each other, and they can rotate freely, but in opposite directions. In the centre of each frame is mounted a prism of $18^{\circ}$; one of the frames is graduated, and when the graduation is at $0^{\circ}$ the axes of the prisms are parallel, so that parallel pencils of rays falling on both are deviated both in the same direction, and still parallel. Thus when the pair of prisms are arranged horizontally in front of a pair of eyes, an object looked at appears displaced up or down, but there is no lateral deviation on either. If the frames be rotated $90^{\circ}$ in one direction, the prisms both have their bases inwards, or, if in the other direction, both outwards, so that two pencils of rays are deviated to the full power of the prisms. In the in termediate positions part of the prismatic effect is resolved in a direction at right angles to the line joining the centres of the frames, and can be neglected as only producing parallel displacement of the image, and part is resolved in the direction of this line so as to produce apparent separation or approximation of the images. This amount is read off from the graduation, which is constructed on the following principle:-Suppose a ray of light X A O perpendicular to the plane of the paper meets the paper at $O$. Suppose a prism be introduced at $A$

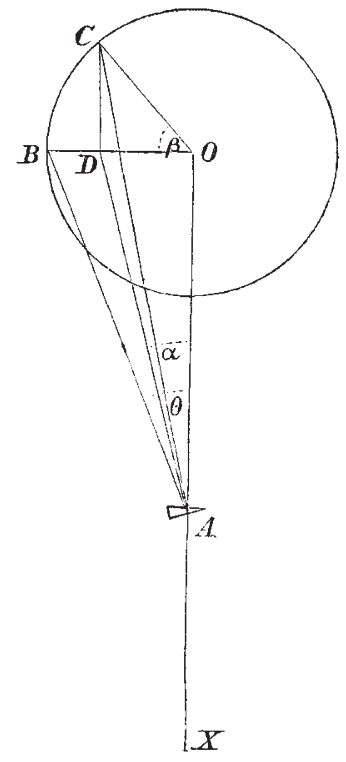

having an angle of deflection $\theta$, the ray of light now falls on the paper at $B$. If the prism be rotated through angle $\beta$, the ray now falls on the paper at $C$. Join $O B, O C$, and resolve $\mathrm{O} C$ into vertical and horizontal co-ordinates $C D, O D$. C D being neglected as described, we wi-h to find OD the horizontal component of the deflection.

$$
\begin{aligned}
\text { Since } O B & =O C \\
\therefore \frac{O D}{O B} & =\frac{O D}{O C} \\
\therefore \frac{O D}{O A} & =\frac{O D}{O C} \\
\frac{\mathrm{OA}}{\tan \alpha} & =\cos \beta \\
\tan \theta & =\operatorname{cog} \tan \alpha-\log \tan \theta .
\end{aligned}
$$

Two other frames are placed in front of the prisms. They contain grooves to hold lenses or combinations of lenses, and are graduated so that cylindrical lenses can be set at any desired angle. The frames can be separated or brought nearer with greater accuracy by a wedge, and the distance of the centres of the glasses is marked on the bearing. The whole is carried at the end of a graduated bar which carries a sliding support for an object. This bar is graduated in inches for use in calculation and also in focal lengths of a set of dioptric lenses. A third prism is attached, so that it can be placed between one of the frames and the object. When it is in position, the rays going through it to the eye appear to come from an object higher than when it is absent. Double vision is produced, and the eyes left free to find their most comfortable position free from any effort to make the two images coalesce. To use the instrument, the spherical and cylindrical elements of the spectacle required are first found either by some of the ordinary methods or by the ophthalmometer described in the Annual Volume for 1880 , and the required lenses from the trial case put in the appropriate frames. The third prism is interposed, and an object, such as a vertical line, looked at at reading distance. If the images seen by the two eyes are exactly one above the other, the prismatic adjustment is presumably correct, the third prism is removed, and trial is made whether reading can be carried on for some time without fatigue. If the images are slightly displaced externally, trial is made whether shifting the centres of the lenses nearer or further off suffices to bring them into position. If so, the distance is noted and sent as a direction to the optician. If the displacement be more than can be corrected by this means, the prisms are rotated till the desired effect is produced, and the amount of prismatic deviation to be given to the proposed spestacles read off. The third prism is removed. and reading practised as above.

\section{SCIENCE AND INDUSTRY ${ }^{1}$}

CONSIDERING the high position in literature and science of my predecessors in this chair, I feel that I have been bold indeed in accepting the distinguished office of President of the Midland Institute during the current year. I shall not attempt to rival my predecessors in those literary or philosophic flights which befitted their powers, but shall confine myself to certain suggestive remarks flowing from personal experience of men and matter, which may prove of some interest to an audience consisting in the main of persons who, like myself, are intent upon combining science with practical aims, but who, unlike myself, have the best part of their career still before them.

In venturing to express my views regarding the great question of the day, that of Technical Education, I shall run considerable risk of disappointing some of its most ardent advocates, who may have looked upon me, a foreigner by birth, as a staunch supporter, if not as the living embodiment, of that particular form of education that the Polytechnicum of Germany and other Continental countries imparts to the aspiring engineer and manufacturer, but which, in my opinion, leaves much to be desired, and is certainly inapplicable to the condition of things which we find in this country.

The subject of education, and of science education in particular, is one the practical and national importance of which it would be difficult to over-estimate. It is well known that the Continental nations have in some respects stolen a march upon us in providing for the education of the young engineer, the architect, the manufacturer, and the craftsman. Colleges of high and low degree abound where buth science and practical processes are taught, whereas the teaching of the latter has been looked on hitherto amongst us as professional or trade knowledge to be acquired during lengthy periods of pupillage or apprenticeship.

The more ardent advocates of the Continental method of technical education go so far as to think that the irksome system of apprenticeship should give way entirely to technical teaching within the college walls, whereby it is assumed much time could be saved and a better knowledge be imparted to the aspiring engineer or manufacturer. Having had some experience of young men brought up at these technical schools, I am bound to say that I have not been favourably impressed with the results produced by that system. The practical knowledge acquired at those establishments is wanting in what may be called the commercial element, that is of due regard to cost of production, of which the teacher himself must be comparatively ignorant, as otlerwise we should find him employed at the factory or engineering office, instead of in the schoolroom.

The young polytechnic student is apt to look on the machine or process which he has studied, not as one of many solutions of a practical problem influenced by ever-varying external circum stances, but as something representing an absolute condition of things almost as completely proved and established as a first

I Abstract of Address at the opening of the Birmingham Midland Institute, by Dr. C. W. Siemens, F.R.S., president of the Institute. 